\title{
Functional and tissue enrichment analyses suggest that SARS-CoV-2 infection affects host metabolism and catabolism mediated by interference on host proteins
}

\author{
Luciano Rodrigo Lopes ${ }^{1}$ (D) \\ Received: 12 November 2020 / Accepted: 8 April 2021 / Published online: 6 May 2021 \\ (C) Sociedade Brasileira de Microbiologia 2021
}

\begin{abstract}
Infection by SARS-CoV-2, the causative agent of COVID-19, is critically connected with host metabolism. Through functional enrichment analysis, the present study aims to evaluate the biological processes involving host proteins interfered by SARS$\mathrm{CoV}-2$ to verify the potential metabolic impact of the infection. Furthermore, tissue enrichment analyses and differential gene expression of host proteins were applied to understand the interference by SARS-CoV-2 on tissue levels. Results based on functional and tissue-specific enrichment analyses, presented in this study, suggest that SARS-CoV-2, mediated interference on host proteins, can affect the metabolism and catabolism of molecular building blocks and control intracellular mechanisms, including gene expression in metabolism-related organs, to support viral demands. Thus, SARS-CoV-2 can broadly affect the host metabolism and catabolism at tissue and physiological levels contributing to a more severe disease.
\end{abstract}

Keywords Coronavirus $\cdot$ SARS-CoV-2 $\cdot$ COVID-19 $\cdot$ Catabolism $\cdot$ Metabolism

\section{Introduction}

Severe acute respiratory syndrome-related coronavirus 2 (SARS-CoV-2), the causative agent of coronavirus disease 2019 (COVID-19), is phylogenetically close to SARS-CoV and Middle East respiratory syndrome-related coronavirus (MERS-CoV) and triggers similar symptoms as observed in SARS and MERS - high fever, cough, sputum production, pneumonia, dyspnea, and acute lung injury with high mortality [1-3]. Although respiratory aspects of COVID-19 have been the main clinical concern, extra-pulmonary alterations frequently occur, including severe inflammatory reaction, kidney failure, acute cardiac injury, arrhythmias, sepsis, and others $[1,4,5]$. Furthermore, central metabolic organs, such

Responsible editor: Giliane Souza Trindade

Luciano Rodrigo Lopes

luciano.lopes@unifesp.br

1 Bioinformatics and Bio-Data Science Division, Health Informatics Department, Universidade Federal de São Paulo-UNIFESP, Rua Botucatu 862 - Prédio Leal Prado (térreo), São Paulo, SP CEP: 04023-062, Brazil as the pancreas and liver, can also be affected by SARS-CoV2 infection [6-8].

Despite the absence of pre-existing immunity against SARS-CoV-2, inflammatory immune reaction has been commonly observed in COVID-19 [9]. Inflammation is essential for host protection, but SARS-CoV-2 infection triggers an aggressive inflammatory response. Consequently a vast set of cytokines (including IL-2, IL-6, IL-7, and TNF) is produced resulting in a cytokine storm [5, 9]. Uncontrolled inflammation inflicts multi-organ damage [10]. Metabolic disorders, such as obesity or diabetes, contribute to immune dysregulation and exacerbate the inflammatory reaction causing homeostasis breakdown during SARS-CoV-2 infection [11]. Moreover, the expression of ACE2 (the receptor for SARS$\mathrm{CoV}-2$ ) is enhanced in diabetic individuals in comparison with non-diabetic ones $[10,12]$. Therefore, the control of the altered metabolism ameliorates the acute effects of SARSCoV-2 and reduces the inflammatory response [10]. Thus, diabetes might contribute to a more prolonged proinflammatory response and deficient control of SARS-CoV-2 replication [13].

Viruses can interfere with the expression of multiple host genes involved in metabolism and biosynthesis of glucose, lipid, and amino acids [14]. The partial control of the host 
metabolism by viral evolved mechanisms, hijacking nutrient, and molecular building blocks from hosts favors the viral replication and persistence [15]. For instance, while cytomegalovirus (CMV) and dengue virus induce the elevation of glucose consumption [14], MERS-CoV, human coronavirus 229E (HCoV-229E), and mouse hepatitis virus (MHV) pick up host lipids to increase replication [16, 17]. Similar to other human viruses, coronaviruses establish molecular interactions with their hosts to take over the cellular mechanisms to support viral replication. Coronaviruses have adaptive benefits to take advantage from the host operating at different organs which disrupt a wide variety of biological processes and pathways $[6,18]$.

Better understanding of the interference of SARS-CoV-2 on host biological processes and the viral impact on the tissue and organs can provide important insight into research and clinical aspects of COVID-19. Thus, the present study attempts to investigate and explore the most affected biological processes which involve host proteins interfered by SARSCoV-2 combined with the tissue-specific differential expression.

\section{Methods}

This study aims to investigate, by enrichment analysis, the biological processes involved in coronaviruses-associated host proteins and their differential expression on tissues and organs. Two sets of host proteins that interact with coronaviruses proteins were included in this study: a set of host proteins associated with SARS-CoV encompassing 64 proteins [19] and a set of host proteins associated with SARS-CoV-2 encompassing 332 proteins [20]. The coronaviruses-associated host proteins included in this work are described in the literature $[19,20]$ and detailed in supplementary table 1.

A tool from g:Profiler [21], g:GOSt, performed the enrichment analyses, based on Gene Ontology (GO) terms, to identify in which pathways and processes the coronavirusesassociated host proteins are implicated. Based on Benjamini-Hochberg False Discovery Rate (FDR) test, the significant biological processes, with $P$-values inferior to 0.01 , were included in the analyses. The heatmap and the differentially expressed gene (DEG) analyses were inferred based on values of gene expression from samples collected from non-diseased tissue sites available on GTEx biobank (https://www.gtexportal.org/home/) which is integrated in FUMA platform [22]. Both analyses were performed using a gene list (supplementary table 1) based on the host proteins associated with SARS-CoV-2. Heatmap included the gene expression values (TPM - transcripts per million) of the 330 genes from 30 tissue types. AATF and CISD3 genes were not available in the database. The heatmap results were based on the expression value $\log 2(\mathrm{TPM}+1)$ per tissue per gene, in which TPM was winsorized at 50, allowing comparison of expression level across genes and tissue types, as described by Watanabe et al. (2017) [22]. Genes were organized by hierarchical clustering. Color gradient varies from dark blue (downregulated, $\min =0$ ) to dark red (upregulated, $\max =5$. 67). In addition, the DEG of 30 tissue types was analyzed using two-sided Student's $t$-tests [22]. Genes with corrected $P$-value inferior to 0.05 were defined as differentially expressed in a specific tissue.

The inference of the relationships between the host protein sets affected by SARS-CoV and SARS-CoV-2 was made using STRING v11 [23]. Both protein sets were included together to construct a protein-protein interaction network predicted by STRING v11. The proteins are represented by the network nodes, and the functional associations between the proteins are represented by the edges. The line thickness indicates the strength of data support (confidence). The network was constructed including 228 host proteins - 64 SARS$\mathrm{CoV}$-associated host proteins (red nodes) and 165 SARS$\mathrm{CoV}-2$-associated host proteins (blue nodes). MAPK3 is presented in both dataset (purple node). Disconnected proteins from the set of host proteins interfered by SARS-CoV-2 were excluded.

An additional analysis to find biological processes and pathways involved with the immune system was conducted by the Reactome pathway database [24] based on SARSCoV-2-associated host proteins. The protein set was used to construct a Voronoi diagram - a pathway map composed by contiguous regions which correspond to the immune systemrelated pathways grouped according to the relationships among pathways specified in the event hierarchy.

\section{Results and discussion}

Figure $1 \mathrm{a}$ and $\mathrm{b}$ represent the biological process categories impacted by coronaviruses infection-metabolism, catabolism, symbiosis, immune response, and a series of intracellular mechanisms (localization, transport/export, organization, cell cycle, and others). Despite COVID-19 and SARS not beingmetabolic diseases, infections by SARS-CoV and SARS-CoV-2 are associated with metabolism disruption [6, $8,25,26]$. In this context, Fig. 1c and d show that the host proteins associated with coronaviruses infection are markedly involved with carbohydrate, protein, and nucleic acid metabolism and catabolism.

Nucleic acid metabolism and catabolism (which include a series of DNA/RNA processing) represent the main category of biological processes impacted by SARS-CoV-2 (Fig. 1c). Viruses usually disrupt the metabolism of nucleotide synthesis favoring the need for rapid viral genome replication [27]. Regulation of catabolism of nucleic acids and their 


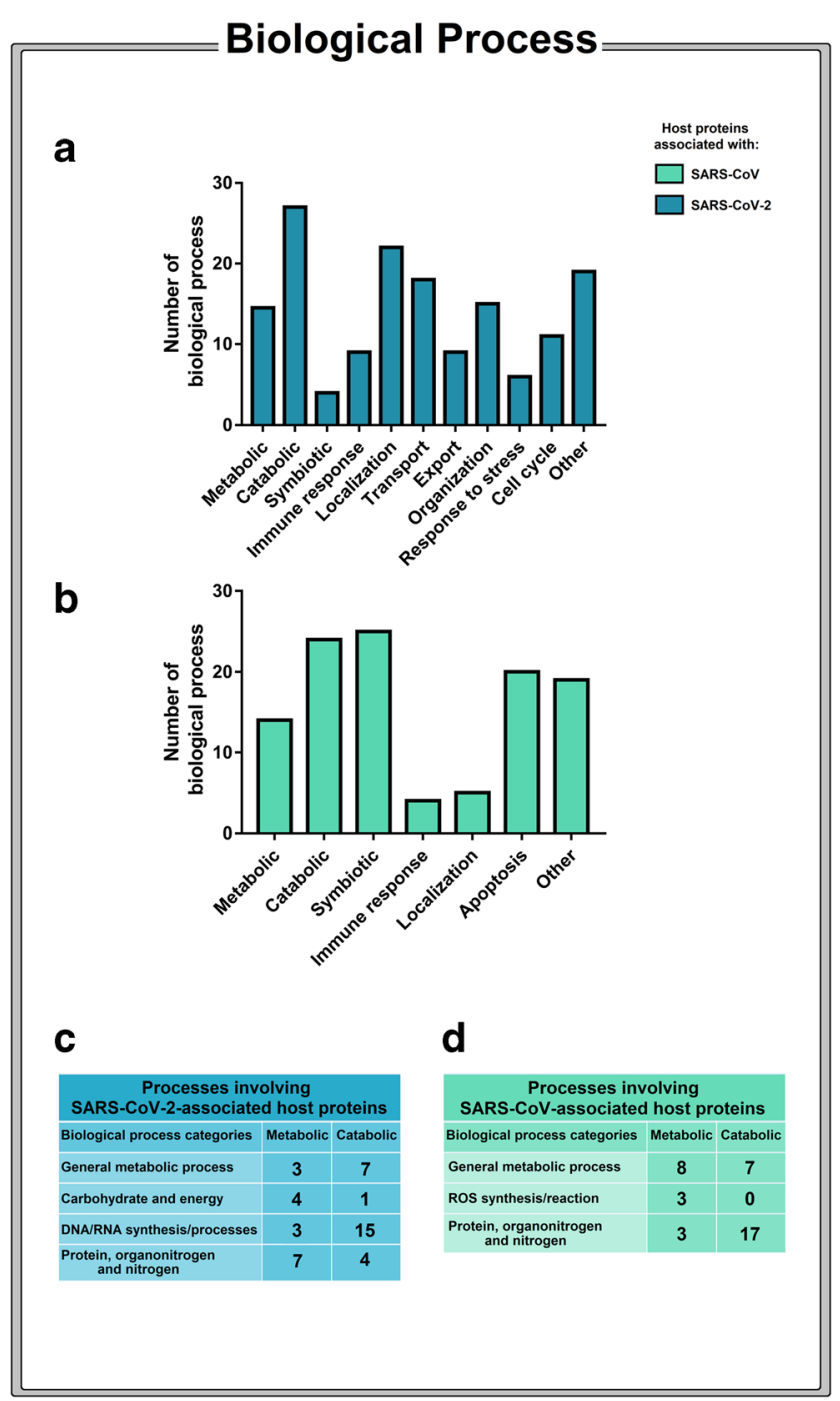

Fig. 1 Biological processes involving coronavirus-associated host proteins. Based on functional enrichment analysis, (a) the main biological process categories related from a set of host proteins affected by SARSCoV-2 are shown in blue column graph, while (b) the biological processes from host proteins affected by SARS-CoV are shown in light-green column graph. The main metabolic and catabolic processes related with SARS-CoV-2 (c) and SARS-CoV (d) are detailed. Two distinct sets based on host proteins which interact with SARS-CoV and SARS-Cov2 were used to infer the biological processes. Host protein sets are available in supplementary table 1 . Biological processes, with $P$-values $<0.01$, based on False Discovery Rate (FDR) test, found by g:Profiler software, were considered as positive. Biological process categories were clustered according to Gene Ontology (GO) term classification. Complete results of biological processes involving coronavirus-associated host proteins revealed by $g: P r o f i l e r$ are available in supplementary table 2 . Graphs were designed with GraphPad Prism 7 (GraphPad Software Inc., San Diego, CA, USA)

metabolites can contribute to viral pathogenesis [28]. For instance, SARS-CoV-2 nsp8 appears to reduce the catabolism capacity of the host exosome complex against viral mRNAs [29]. In addition, components of exosome complex (EXOSC2, EXOSC3, EXOSC5, and EXOSC8) included in the set of SARS-CoV-2-associated host proteins presented highlighted function involving nucleic acid catabolism processes (supplementary table 2).

Another nucleic acid disruption occurs during infection of avian coronavirus (infectious bronchitis virus-IBV). IBV controls the cell cycle and forces cells into the $\mathrm{S}$ phase to ensure an abundant supply of nucleotides during the viral replication enhancing progeny production [30]. SARS-CoV $\mathrm{N}$ protein manipulates the cell cycle and blocks the progression of the $\mathrm{S}$ phase [31]. The cell cycle is also affected during SARS-CoV-2 infection. SARS-CoV-2, mediated E protein, interacts with BRD4 interfering in the cell cycle [32]. BRD4 is required by herpes simplex vírus (HSV), for example, to favor viral replication [33]. In addition, inhibition of BRD4 was associated with broad antiviral activity [34]. According to enrichment analysis results, SARS-CoV-2-associated host proteins, including BRD4, are involved in cell cycle processes (Fig. 1a and supplementary table 2).

The interference in nucleic acid metabolism and catabolism can potentially affect the regulation of host cellular mRNAs and increase the translation of viral mRNAs. Viruses can manipulate and regulate many steps in gene expression: transcription, mRNA processing, mRNA export from the nucleus, regulation of mRNA stability, and translation [35]. SARS$\mathrm{CoV}-2 \mathrm{~N}$ protein interacts with UPF1 and PABPC1 proteins interfering with host cellular processes of mRNA degradation [36]. Both host proteins interfered by SARS-CoV-2 are associated with transcriptional processes shown in enrichment analysis results (supplementary table 2). Previous studies show that SARS-CoV and SARS-CoV-2 can disrupt the host genetic expression to escape from the immune system [37, 38]. While SARS-CoV reduces the innate immunity response blocking the interferons and NFKB expression [37], SARSCoV-2 suppresses antiviral defenses inhibiting the global translation of host mRNA and disturbing the protein trafficking to the cell membrane [38]. In parallel, energy metabolismassociated genes were upregulated during SARS-CoV-2 infection, promoting viral replication [39].

The expression of each SARS-CoV-2-associated host protein per tissue is shown in the heatmaps (Fig. 2a). The genetic expressions in tissues/organs that presented discrepant patterns - upregulated and downregulated - compared with other tissues were included in separate columns ("UP" and "DOWN"). Many genes were pointed out (high/red or low/ blue), and further analysis of each of them would be necessary to understand the role of those genes on each tissue/organ. The DEG analyses indicate that SARS-CoV-2-associated host proteins are significantly upregulated in the cervix, uterus, and ovary but downregulated in the blood, brain, heart, kidney, liver, muscle, and pancreas in physiological status (red columns in Fig. 2b and c). As said before, infections by coronaviruses lead to functional disruptions of metabolic tissues or organs $[6,25,40]$. Here, the ubiquitous presence of ACE2 (angiotensin-converting enzyme 2) host receptors [41] 
Fig. 2 Heatmap based on gene expression (a) demonstrates the average expression values of the 330 genes from 30 tissue types. The heatmap results were based on the expression value $\log 2(\mathrm{TPM}+1)$ per tissue per gene. Color gradient varies from dark blue (downregulated, $\min =0$ ) to dark red (upregulated, $\max =$ 5.67). Based on differential genetic expression, two columns were highlighted from the right side of heat maps "DOWN" (downregulated genes per tissue/ organ) and "UP" (upregulated genes per tissue/organ). The differential genetic expression analyses are presented in column graphs $(\mathbf{b}, \mathbf{c})$. Differentially downregulated expressed gene sets (b) are shown in the pancreas, heart, liver, kidney, blood, muscle, and brain. On the other hand, the uterus, cervix, and ovary had upregulated expressed gene sets differentially $(\mathbf{c})$. The genes whose expression had significant discrepancy (high or lower) in a given tissue compared to others for each of 30 tissue types, highlighted in red, are considered differentially expressed ( $P$-value with Bonferroni is $<0.05)$. AATF and CISD3 were not available in the database to be included in heatmaps

\section{Tissue-Specific Expression of Genes Impacted by SARS-CoV-2}

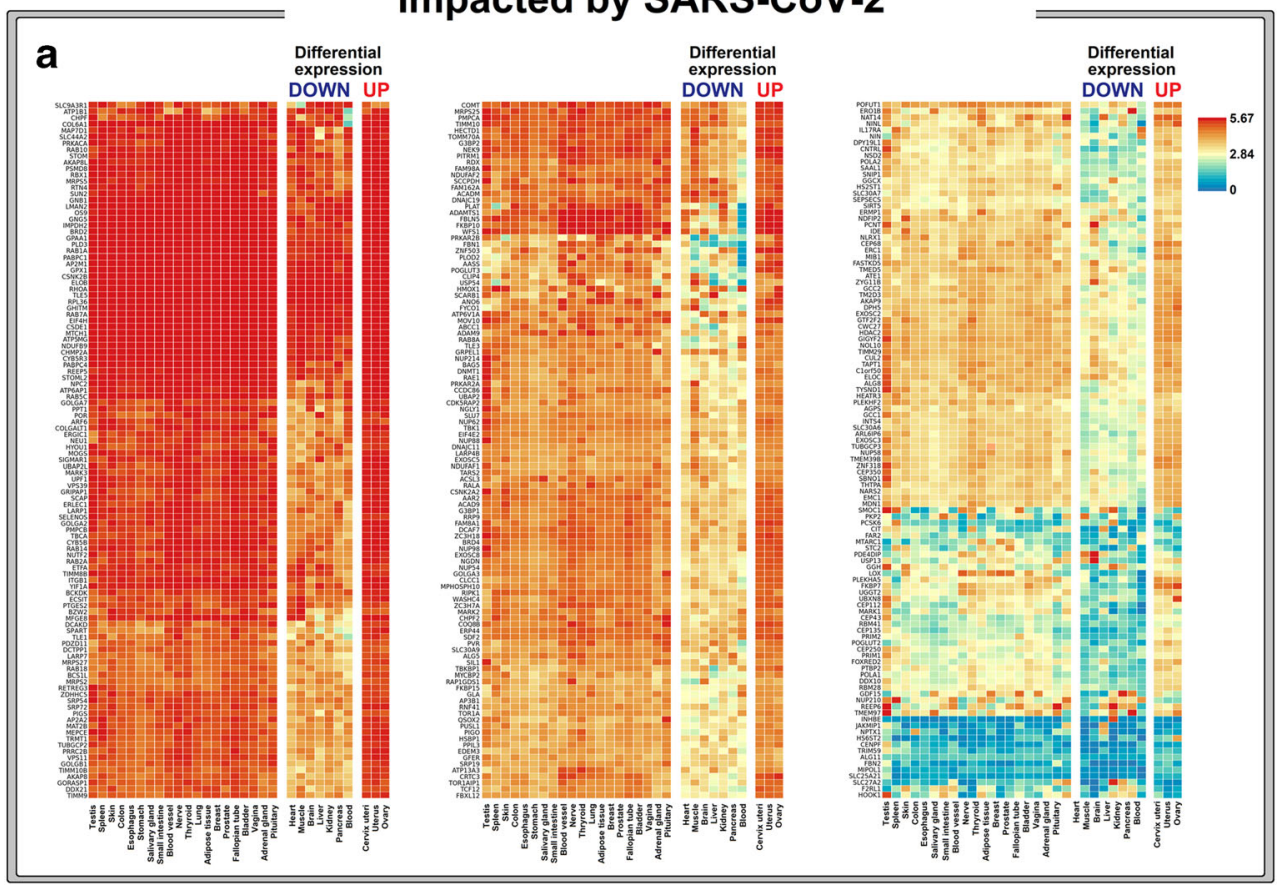

Differential Expression Gene

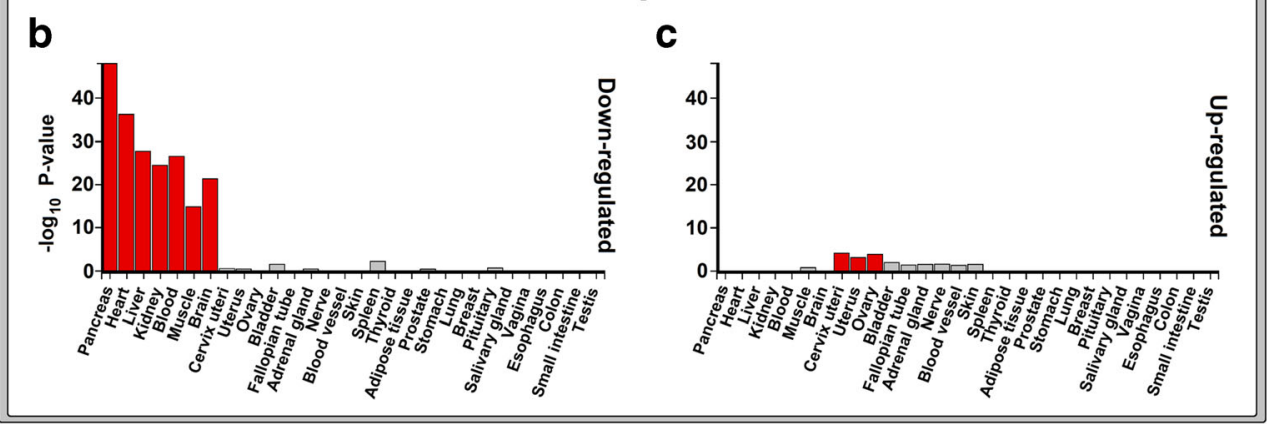

provides opportunities for the virus to access these metabolic organs. Then, SARS-CoV-2 can enter and manipulate a series of intracellular mechanisms altering metabolism and catabolism.

This study shows that SARS-CoV-2-associated host proteins are also involved with energy metabolism and catabolism (Fig. 1c). SARS-CoV-2 might alter the host metabolism to uptake energy to support the replication. This strategy is usually observed in some viruses to hijack the host energy metabolism [14]. Enterovirus 71, for example, upregulates the energy metabolism to increase glycolysis utilization [42]. However, when glucose metabolism is inhibited, viral replication capacity becomes impaired [14]. Inhibition of glycolysis suppresses SARS-CoV-2 replication [43], suggesting that SARS-CoV-2 depends on increased glucose. SARS-CoV-2 seems to modulate the host protein repertoire to its benefits, as well as CMV. During infection by CMV, transcript levels of glycolytic enzymes are increased. Infected cells, in comparison with uninfected cells, presented elevated levels of metabolites derived from glycolysis and the citric acid cycle [44]. In addition, some viruses can modify the demands of the host through the regulation of host gene expression $[45,46]$. Similarly, hepatitis C virus (HCV), for example, upregulates the expression of metabolism genes that may act as important factors for the HCV replication cycle [46]. In agreement, Fig. $2 \mathrm{a}$ and $\mathrm{b}$ shows that SARS-CoV-2-associated host genes are significantly downregulated on organs that regulate glucose, such as the pancreas, liver, and muscular system. The potential interference of SARS-CoV-2 on these organs may shift up the host proteins expression to elevate the host energetic offering.

The increased glycolysis provided by viruses is not solely required for virus assembly and replication but also may favor host cellular survival [27]. To keep the cell alive and increase replication resources, other coronaviruses than SARS-CoV-2 
can take over the cell cycle and manipulate apoptosis [30]. In comparison to SARS-CoV, SARS-CoV-2 has relatively weaker pro-apoptotic activity [47]. In agreement, Fig. 1 a and $b$ show that cell cycle and apoptotic processes are involved with SARS-CoV-2 and SARS-CoV-associated host proteins, respectively. Additionally, IBV alters the subcellular localization of p53, delaying the onset of apoptosis in infected cells [48]. Despite SARS-CoV-2 interferes with host proteins involved in apoptosis (such as AATF, MITCH1, and RPK1), results did not show significant apoptotic processes related to it. Thus, SARS-CoV-2 potentially manipulates the cell cycle, dysregulating the host cell survival, while presents a weaker impact on apoptosis, to create a beneficial environment for replication and propagation.

In addition to interference in cell cycle processes, coronaviruses also interfere in host proteins involved in several intracellular mechanisms - transport, localization, and organization mechanisms (Fig. 1a and b). SARS-CoV, MERS$\mathrm{CoV}$, and MHV, using nsp1 protein, can destabilize the host mRNA, while viral mRNA remains stable [49-51]. Furthermore, nsp1 protein alters subcellular localization of nucleoporin complex components and affects nuclearcytoplasmic localization of host mRNA [49]. SARS-CoV can also alter viral protein localization actively, exporting them from nucleus to endoplasmic reticulum-Golgi to favor virion assembly [52]. Therefore, coronaviruses seem to interfere in several intracellular mechanisms which can conduct the host metabolism and catabolism to improve viral assembly, replication, and infectivity.

Additionally, SARS-CoV and SARS-CoV-2 may impact protein metabolism and catabolism. Figure $1 \mathrm{c}$ and $\mathrm{d}$ show that protein metabolic and catabolic processes are rather affected than energy or fat. For instance, depletion of protein stores influences many aspects of morbidity and mortality from infectious diseases [53]. To support the large amounts of viral replication, the influenza virus appears to obtain essential amino acids reducing their levels in infected tissues [28]. Similarly, in this context, HIV-1 also induces a deep effect in host protein metabolism to sustain the replication [54]. Taken together, the interference of SARS-CoV and SARS$\mathrm{CoV}-2$ on protein metabolic and catabolic processes presented here may reflect the demand for synthesis of viral proteins. Viral proteins are preferentially synthesized instead of host cell proteins. Acquisition of molecular building blocks from the host to viral replication machinery leads to disruption of physiological processes [35].

Disrupted protein metabolism and catabolism by SARSCoV-2 seem to have significant implications. In liver cells, SARS-CoV-2 appears to inhibit protein synthesis [55]. Consequently, the levels of albumin and coagulation factors may be reduced [55-57]. The lack of protein synthesis by the liver has been associated with the severity of COVID-19 and poor prognosis [55]. Figure $2 \mathrm{a}$ and $\mathrm{b}$ show differential expression of SARS-CoV-2-associated host proteins in the liver, which may corroborate the viral influence in hypoalbuminemia and impairment of coagulation factor synthesis. In addition, the significant interference of SARS-CoV-2 on host metabolism and catabolism of protein, presented in this study by tissue enrichment analyses, might be a possible explanation for protein catabolic processes that promote muscle mass losses, resulting in sarcopenia followed by respiratory and cardiac function impairment in patients with COVID-19 [58]. SARS-CoV-2 respiratory infection can potentially impact the musculoskeletal system [59], which is considered an important store for protein able to regulate levels of amino acids and glucose in the circulation [60].

Tissue enrichment analyses indicate that differential expression of host proteins can occur in the heart and kidney as well (Fig. 2a and b). The presence of SARS-CoV-2 has been documented in the myocardium, being also actively replicating in the heart [61]. Although protein metabolism or catabolism alterations were not reported in the heart from COVID-19 patients, SARS-CoV-2 appears to induce direct myocardial damage and stimulate inflammatory reaction followed by a cytokine storm [61, 62]. Acute viral myocarditis and cytokine cardiomyopathy can be found together with renal dysfunction [63]. Protein leakage resulting from tubular damage by SARS-CoV-2 has been reported [63]. The tissue injuries mediated by SARS-CoV-2 and the hyperinflammatory response have a significant role to the severity of the infection $[62,63]$. In general, excessive proinflammatory cytokines can result in protein catabolism, organ failure, and, subsequently, death [53]. Thus, the combination between protein catabolism and metabolism with elevated production of proinflammatory cytokines potentially increases the severity of COVID-19 progression.

Comparing the coronavirus impact on the host (Fig. 1a and b), SARS-CoV seems to affect symbiotic processes more expressively than SARS-CoV-2. The results can partially explain the bad prognosis of SARS-CoV-infected patients and the high mortality rate of SARS when compared to COVID19 [64, 65]. Although SARS-CoV and SARS-CoV-2 have been associated with different sets of host proteins (supplementary table 1), both protein sets showed close relationships (supplementary figure 1). This result suggests that SARS-CoV and SARS-CoV-2 could affect the same pathways but at different points contributing to different pathogenesis mechanisms by both coronaviruses.

Symbiotic processes implicate the balance or disruption of host organism structures or processes mediated by another one [66]. The symbiotic processes suggest the harmful disequilibrium extended to humans, while coronavirus-specific immune response is absent. Although the enrichment analyses show that coronavirus-associated host proteins are involved in a few processes of the immune system, COVID-19 progression is related to inadequate immune response, especially 
encompassing cytokine hyperproduction and exacerbated inflammation $[1,6]$. Despite the restricted number of immune system processes involving SARS-CoV-2 host proteins, the results revealed neutrophil involvement in immune system processes (supplementary table 2 and Table 1). The limitation to find robust significant results associated with the immune system may be due to a subtle biological signal of the molecular set applied. Although the analysis of gene sets on enrichment analysis enhances the statistical power of the method, broader terms such as immune response processes can require a larger list of related genes to be enriched [67]. Alternatively, to investigate the immunological role of the host protein set interfered during SARS-CoV-2 infection, an additional analysis using Reactome pathway database was performed (supplementary figure 2). A Voronoi diagram was constructed based on the hierarchical representation of pathways and biological processes, including immune system activities. However, significant immunological pathways are poorly represented. Neutrophil involvement is also highlighted here, corroborating the previous results. This granulocyte has an important role in the COVID-19 cytokines storm [68, 69], and neutrophils exhibit an intense response during SARSCoV-2 infection, including an exacerbated production of inflammatory molecules [68].

The inflammatory state caused by SARS-CoV-2 could alter the microenvironment of immune tolerance needed in pregnancy [70]. However, the impact of SARS-CoV-2 in pregnancy is not entirely clear [71], and vertical transmission was not reported at the present moment. The female reproductive system appears to not be affected during COVID-19 [72]. The expression of ACE2 and TMPRSS2 is reduced in the uterus and ovary [73]. This fact suggests the low potential of infection by SARS-CoV-2 on the uterus and ovary. On the other hand, SARS-CoV-2 was already detected in these

Table 1 Immune system processes involving SARS-CoV-2-associated host proteins
Immune system processes involving SARS-CoV-2-associated host proteins

Granulocyte activation

Leukocyte degranulation

Myeloid cell activation involved in immune response

Myeloid leukocyte activation

Myeloid leukocyte mediated immunity

Neutrophil activation

Neutrophil activation involved in immune response

Neutrophil degranulation

Neutrophil mediated immunity

The results were obtained using g:Profiler software and are fully available in supplementary table 2 organs [74]. High levels of glucose stored in the uterus [75] promoted by ovarian hormones, which also leads to protein catabolism [76], may favor the permanence of SARS-CoV-2. Significant upregulation of SARS-CoV-2-associated host proteins in the uterus, cervix, and ovary (Fig. 2 a and c) which involve broad metabolic and catabolic processes may be convenient to viral persistence on those organs. However, this issue must be elucidated for further studies, as well as the long-term effects of COVID-19 on female fertility and pregnancy.

SARS-CoV-2 infection and the host metabolism are intimately connected. SARS-CoV-2 might trigger stress conditions and increased secretion of hyperglycemic hormones in diabetic patients, elevating blood glucose level [77]. Hyperglycemia via insulin resistance in diabetic patients or even in obese individuals induces elevated levels of inflammatory cytokines [78]. Consequently, metabolic diseases induce a dysregulated immune response state that can affect the response to pathogens $[10,13]$. Hyperimmune conditions in diabetes and obesity appear to exacerbate the cytokine storm triggered by SARS-CoV-2 [10, 78, 79]. Moreover, ACE2 was highly expressed in diabetic and obese individuals in comparison with control individuals $[78,80]$. Taken together, COVID-19 patient with a previous metabolic disturbance, such as diabetes or obesity, presents greater risk to develop a more severe infection course than people who are metabolically healthy before acquiring the infection $[6,10,26]$. The broad interference of SARS-CoV-2 on the host catabolism and metabolism, and the potential functional disruption on metabolism-related organs, shown in this study, can be substantially harmful to patients presenting comorbidities.

The combination between functional and tissue-specific enrichment analyses, presented in this study, suggests that SARS-CoV-2 through interference on host proteins affects metabolism and catabolism of molecular building blocks and alters intracellular mechanisms, including gene expression, to support viral demands. SARS-CoV-2 regulation of gene expression in organs with a central role on host metabolism may shift COVID-19 towards a more severe and critical stage. Concomitantly, catabolism can impair the progression of the disease. Thus, catabolic response, as metabolic response, induced by coronavirus should be considered a clinical concern during the course of COVID-19.

Supplementary Information The online version contains supplementary material available at https://doi.org/10.1007/s42770-021-00497-0.

Acknowledgements The author thank Mr. Vitor Machado Tonini, Mr. Maurício Roberto Lopes, Msc Antonio Carlos da Silva Junior, Msc Giancarlo de Mattos Cardillo, and Msc João Henrique Campos for the scientific and language revision. Especial thanks to Professor Meide Silva Anção, Health Informatics Department and Universidade Federal de São Paulo-UNIFESP fortheir support. 


\section{Declarations}

Ethics approval This research included secondary biological data with no possibility of individual identification. The Unifesp Research Ethics Committee was consulted and determined that this study did not require ethical approval.

Conflict of interest The author declares no competing interests.

\section{References}

1. da Costa VG, Moreli ML, Saivish MV (2020) The emergence of SARS, MERS and novel SARS-2 coronaviruses in the 21st century. Arch Virol 65(7):1517-1526. https://doi.org/10.1007/s00705020-04628-0

2. Harb JG, Noureldine HA, Chedid G, Eldine MN, Abdallah DA, Chedid NF et al (2020) SARS, MERS and COVID-19: clinical manifestations and organ-system complications: a mini review. Pathog Dis 78(4):ftaa033. https://doi.org/10.1093/femspd/ftaa033

3. Liu J, Zheng X, Tong Q, Li W, Wang B, Sutter K, Trilling M, Lu M, Dittmer U, Yang D (2020) Overlapping and discrete aspects of the pathology and pathogenesis of the emerging human pathogenic coronaviruses SARS-CoV, MERS-CoV, and 2019-nCoV. J Med Virol 92(5):491-494. https://doi.org/10.1002/jmv.25709

4. Hossain MF, Hasana S, Mamun AA, Uddin MS, Wahed MII, Sarker S, Behl T, Ullah I, Begum Y, Bulbul IJ, Amran MS, Rahman MH, Bin-Jumah MN, Alkahtani S, Mousa SA, Aleya L, Abdel-Daim MM (2020) COVID-19 outbreak: pathogenesis, current therapies, and potentials for future management. Front Pharmacol 11:563478. https://doi.org/10.3389/fphar.2020.563478

5. Harrison AG, Lin T, Wang P (2020) Mechanisms of SARS-CoV-2 transmission and pathogenesis. Trends Immunol 41(12):1100 1115. https://doi.org/10.1016/j.it.2020.10.004

6. Ayres JS (2020) A metabolic handbook for the COVID-19 pandemic. Nat Metab. 1-14. 2(7):572-585. doi: https://doi.org/10. 1038/s42255-020-0237-2.

7. Samanta J, Gupta R, Singh MP, Patnaik I, Kumar A, Kochhar R (2020) Coronavirus disease 2019 and the pancreas. Pancreatology 20(8):1567-1575. https://doi.org/10.1016/j.pan.2020.10.035

8. He B, Wang J, Wang Y, Zhao J, Huang J, Tian Y, Yang C, Zhang H, Zhang M, Gu L, Zhou X, Zhou J (2020) The metabolic changes and immune profiles in patients with COVID-19. Front Immunol 11:2075. https://doi.org/10.3389/fimmu.2020.02075

9. Tay MZ, Poh CM, Rénia L, MacAry PA, Ng LFP (2020) The trinity of COVID-19: immunity, inflammation and intervention. Nat Rev Immunol 20(6):363-374. https://doi.org/10.1038/ s41577-020-0311-8

10. Bornstein SR, Dalan R, Hopkins D, Mingrone G, Boehm BO (2020) Endocrine and metabolic link to coronavirus infection. Nat Rev Endocrinol 16(6):297-298. https://doi.org/10.1038/s41574020-0353-9

11. Pasquarelli-do-Nascimento G, Braz-de-Melo HA, Faria SS, de Santos IO, Kobinger GP, Magalhães KG (2020) Hypercoagulopathy and adipose tissue exacerbated inflammation may explain higher mortality in COVID-19 patients with obesity. Front Endocrinol 11:530. https://doi.org/10.3389/fendo.2020. 00530

12. Wijnant SRA, Jacobs M, Eeckhoutte HPV, Lapauw B, Joos GF, Bracke KR et al (2020) Expression of ACE2, the SARS-CoV-2 receptor, in lung tissue of patients with type 2 diabetes. Diabetes 69(12):2691-2699. https://doi.org/10.2337/db20-0669
13. Hussain A, Bhowmik B, do Vale Moreira NC (2020) COVID-19 and diabetes: knowledge in progress. Diabetes Res Clin Pract 162: 108142. https://doi.org/10.1016/j.diabres.2020.108142

14. Thaker SK, Ch'ng J, Christofk HR (2019) Viral hijacking of cellular metabolism. BMC Biol 17(1):59. https://doi.org/10.1186/ s12915-019-0678-9

15. Goodwin CM, Xu S, Munger J (2015) Stealing the keys to the kitchen: viral manipulation of the host cell metabolic network. Trends Microbiol 23(12):789-798. https://doi.org/10.1016/j.tim. 2015.08.007

16. Thorp EB, Boscarino JA, Logan HL, Goletz JT, Gallagher TM (2006) Palmitoylations on murine coronavirus spike proteins are essential for virion assembly and infectivity. J Virol 80(3):1280 1289. https://doi.org/10.1128/JVI.80.3.1280-1289.2006

17. Yan B, Chu H, Yang D, Sze K-H, Lai P-M, Yuan S, Shuai H, Wang Y, Kao RYT, Chan JFW, Yuen KY (2019) Characterization of the lipidomic profile of human coronavirus-infected cells: implications for lipid metabolism remodeling upon coronavirus replication. Viruses. 11(1):73. https://doi.org/10.3390/v11010073

18. Prasad A, Prasad M (2020) Single virus targeting multiple organs: what we know and where we are heading? Front Med 7:370. https:// doi.org/10.3389/fmed.2020.00370

19. Zhou Y, Hou Y, Shen J, Huang Y, Martin W, Cheng F (2020) Network-based drug repurposing for novel coronavirus 2019nCoV/SARS-CoV-2. Cell Discov 6:14. https://doi.org/10.1038/ s41421-020-0153-3

20. Gordon DE, Jang GM, Bouhaddou M, Xu J, Obernier K, White KM, O’Meara MJ, Rezelj VV, Guo JZ, Swaney DL, Tummino TA, Hüttenhain R, Kaake RM, Richards AL, Tutuncuoglu B, Foussard H, Batra J, Haas K, Modak M, Kim M, Haas P, Polacco BJ, Braberg H, Fabius JM, Eckhardt M, Soucheray M, Bennett MJ, Cakir M, McGregor MJ, Li Q, Meyer B, Roesch F, Vallet T, Mac Kain A, Miorin L, Moreno E, Naing ZZC, Zhou Y, Peng S, Shi Y, Zhang Z, Shen W, Kirby IT, Melnyk JE, Chorba JS, Lou K, Dai SA, BarrioHernandez I, Memon D, Hernandez-Armenta C, Lyu J, Mathy CJP, Perica T, Pilla KB, Ganesan SJ, Saltzberg DJ, Rakesh R, Liu X, Rosenthal SB, Calviello L, Venkataramanan S, Liboy-Lugo J, Lin Y, Huang XP, Liu YF, Wankowicz SA, Bohn M, Safari M, Ugur FS, Koh C, Savar NS, Tran QD, Shengjuler D, Fletcher SJ, O'Neal MC, Cai Y, Chang JCJ, Broadhurst DJ, Klippsten S, Sharp PP, Wenzell NA, Kuzuoglu-Ozturk D, Wang HY, Trenker R, Young JM, Cavero DA, Hiatt J, Roth TL, Rathore U, Subramanian A, Noack J, Hubert M, Stroud RM, Frankel AD, Rosenberg OS, Verba KA, Agard DA, Ott M, Emerman M, Jura N, von Zastrow M, Verdin E, Ashworth A, Schwartz O, d'Enfert C, Mukherjee S, Jacobson M, Malik HS, Fujimori DG, Ideker T, Craik CS, Floor SN, Fraser JS, Gross JD, Sali A, Roth BL, Ruggero D, Taunton J, Kortemme T, Beltrao P, Vignuzzi M, García-Sastre A, Shokat KM, Shoichet BK, Krogan NJ (2020) A SARS-CoV-2 protein interaction map reveals targets for drug repurposing. Nature 583(7816): 459-468. https://doi.org/10.1038/s41586-020-2286-9

21. Raudvere U, Kolberg L, Kuzmin I, Arak T, Adler P, Peterson H, Vilo J (2019) g:Profiler: a web server for functional enrichment analysis and conversions of gene lists (2019 update). Nucleic Acids Res 47(W1):W191-W198. https://doi.org/10.1093/nar/ gkz369

22. Watanabe K, Taskesen E, van Bochoven A, Posthuma D (2017) Functional mapping and annotation of genetic associations with FUMA. Nat Commun 8(1):1826. https://doi.org/10.1038/s41467017-01261-5

23. Szklarczyk D, Gable AL, Lyon D, Junge A, Wyder S, HuertaCepas J, Simonovic M, Doncheva NT, Morris JH, Bork P, Jensen LJ, Mering C (2019) STRING v11: protein-protein association networks with increased coverage, supporting functional discovery in genome-wide experimental datasets. Nucleic Acids Res 47(D1): D607-D613. https://doi.org/10.1093/nar/gky1131 
24. Jassal B, Matthews L, Viteri G, Gong C, Lorente P, Fabregat A, Sidiropoulos K, Cook J, Gillespie M, Haw R, Loney F, May B, Milacic M, Rothfels K, Sevilla C, Shamovsky V, Shorser S, Varusai T, Weiser J, Wu G, Stein L, Hermjakob H, D'Eustachio P (2020) The reactome pathway knowledgebase. Nucleic Acids Res 48(D1):D498-D503. https://doi.org/10.1093/nar/gkz1031

25. An Y-W, Song S, Li W-X, Chen Y-X, Hu X-P, Zhao J, Li ZW, Jiang GY, Wang C, Wang JC, Yuan B, Liu HQ (2021) Liver function recovery of COVID-19 patients after discharge, a follow-up study. Int J Med Sci 18(1):176-186. https://doi.org/10.7150/ijms. 50691

26. Chocair PR, de Neves PDM M, Pereira LVB, Mohrbacher S, Oliveira ES, Nardotto LL, et al. (2020) Covid-19 and metabolic syndrome. Rev Assoc Médica Bras 66(7):871-875. https://doi. org/10.1590/1806-9282.66.7.871.

27. Sanchez EL, Lagunoff M (2015) Viral activation of cellular metabolism. Virology 479-480:609-618. https://doi.org/10.1016/j.virol. 2015.02.038

28. Keshavarz M, Solaymani-Mohammadi F, Namdari H, Arjeini Y, Mousavi MJ, Rezaei F (2020) Metabolic host response and therapeutic approaches to influenza infection. Cell Mol Biol Lett 25:15. https://doi.org/10.1186/s11658-020-00211-2

29. Turjya RR, Khan MA-A-K, Islam ABMMK (2020) Perversely expressed long noncoding RNAs can alter host response and viral proliferation in SARS-CoV-2 infection. Futur Virol 15(9):577593. https://doi.org/10.2217/fvl-2020-0188

30. Xu LH, Huang M, Fang SG, Liu DX (2011) Coronavirus infection induces DNA replication stress partly through interaction of its nonstructural protein 13 with the 125 subunit of DNA polymerase

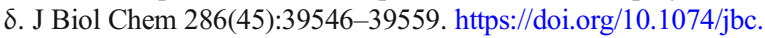
M111.242206

31. Su M, Chen Y, Qi S, Shi D, Feng L, Sun D (2020) A mini-review on cell cycle regulation of coronavirus infection. Front Vet Sci 7: 586826. https://doi.org/10.3389/fvets.2020.586826

32. Feng L, Yin Y-Y, Liu C-H, Xu K-R, Li Q-R, Wu J-R, et al. (2020) Proteome-wide data analysis reveals tissue-specific network associated with SARS-CoV-2 infection. J Mol Cell Biol mjaa033. doi: https://doi.org/10.1093/jmcb/mjaa033.

33. Ren K, Zhang W, Chen X, Ma Y, Dai Y, Fan Y, Hou Y, Tan RX, Li E (2016) An epigenetic compound library screen identifies BET inhibitors that promote HSV-1 and -2 replication by bridging P$\mathrm{TEFb}$ to viral gene promoters through BRD4. PLoS Pathog 12(10):e1005950. https://doi.org/10.1371/journal.ppat.1005950

34. Wang J, Li G-L, Ming S-L, Wang C-F, Shi L-J, Su B-Q, Wu HT, Zeng L, Han YQ, Liu ZH, Jiang DW, du YK, Li XD, Zhang GP, Yang GY, Chu BB (2020) BRD4 inhibition exerts anti-viral activity through DNA damage-dependent innate immune responses. PLoS Pathog 16(3):e1008429. https://doi.org/10.1371/journal. ppat. 1008429

35. Rivas HG, Schmaling SK, Gaglia MM (2016) Shutoff of host gene expression in influenza A virus and herpesviruses: similar mechanisms and common themes. Viruses 8(4):102. https://doi.org/10. 3390/v8040102

36. Sirpilla O, Bauss J, Gupta R, Underwood A, Qutob D, Freeland T, Bupp C, Carcillo J, Hartog N, Rajasekaran S, Prokop JW (2020) SARS-CoV-2-encoded proteome and human genetics: from interaction-based to ribosomal biology impact on disease and risk processes. J Proteome Res 19(11):4275-4290. https://doi.org/10. 1021/acs.jproteome.0c00421

37. Frieman M, Heise M, Baric R (2008) SARS coronavirus and innate immunity. Virus Res 133(1):101-112. https://doi.org/10.1016/j. virusres.2007.03.015

38. Banerjee AK, Blanco MR, Bruce EA, Honson DD, Chen LM, Chow A et al (2020) SARS-CoV-2 disrupts splicing, translation, and protein trafficking to suppress host defenses. Cell 183(5):13251339. e21. https://doi.org/10.1016/j.cell.2020.10.004
39. Codo AC, Davanzo GG, de Monteiro LB, de Souza GF, Muraro SP, Virgilio-da-Silva JV et al (2020) Elevated glucose levels favor SARS-CoV-2 infection and monocyte response through a HIF- $1 \alpha /$ glycolysis-dependent axis. Cell Metab 32(3):437-446. e5. https:// doi.org/10.1016/j.cmet.2020.07.007

40. Mori J, Oudit GY, Lopaschuk GD (2020) SARS-CoV-2 perturbs the renin-angiotensin system and energy metabolism. Am J Physiol-Endocrinol Metab 319(1):E43-E47. https://doi.org/10. 1152/ajpendo.00219.2020

41. Verdecchia P, Cavallini C, Spanevello A, Angeli F (2020) The pivotal link between ACE2 deficiency and SARS-CoV-2 infection. Eur J Intern Med 76:14-20. https://doi.org/10.1016/j.ejim.2020.04. 037

42. Cheng M-L, Chien K-Y, Lai C-H, Li G-J, Lin J-F, Ho H-Y (2020) Metabolic reprogramming of host cells in response to enteroviral infection. Cells 9(2):473. https://doi.org/10.3390/cells9020473

43. Bojkova D, Klann K, Koch B, Widera M, Krause D, Ciesek S, Cinatl J, Münch C (2020) Proteomics of SARS-CoV-2-infected host cells reveals therapy targets. Nature 583(7816):469-472. https://doi.org/10.1038/s41586-020-2332-7

44. Munger J, Bajad SU, Coller HA, Shenk T, Rabinowitz JD (2006) Dynamics of the cellular metabolome during human cytomegalovirus infection. PLoS Pathog 2(12):e132. https://doi.org/10.1371/ journal.ppat.0020132

45. Aranda M, Maule A (1998) Virus-induced host gene shutoff in animals and plants. Virology 243(2):261-267. https://doi.org/10. 1006/viro.1998.9032

46. Blackham S, Baillie A, Al-Hababi F, Remlinger K, You S, Hamatake R et al (2010) Gene expression profiling indicates the roles of host oxidative stress, apoptosis, lipid metabolism, and intracellular transport genes in the replication of hepatitis $\mathrm{C}$ virus. $\mathrm{J}$ Virol 84(10):5404-5414. https://doi.org/10.1128/JVI.02529-09

47. Ren Y, Shu T, Wu D, Mu J, Wang C, Huang M, Han Y, Zhang XY, Zhou W, Qiu Y, Zhou X (2020) The ORF3a protein of SARS-CoV2 induces apoptosis in cells. Cell Mol Immunol 17(8):881-883. https://doi.org/10.1038/s41423-020-0485-9

48. Dove B, Brooks G, Bicknell K, Wurm T, Hiscox JA (2006) Cell cycle perturbations induced by infection with the coronavirus infectious bronchitis virus and their effect on virus replication. J Virol 80(8):4147-4156. https://doi.org/10.1128/JVI.80.8.4147-4156. 2006

49. Gomez GN, Abrar F, Dodhia MP, Gonzalez FG, Nag A (2019) SARS coronavirus protein nsp1 disrupts localization of Nup93 from the nuclear pore complex. Biochem Cell Biol Biochim Biol Cell 97(6):758-766. https://doi.org/10.1139/bcb-2018-0394

50. Terada Y, Kawachi K, Matsuura Y, Kamitani W (2017) MERS coronavirus nsp1 participates in an efficient propagation through a specific interaction with viral RNA. Virology 511:95-105. https:// doi.org/10.1016/j.virol.2017.08.026

51. Züst R, Cervantes-Barragán L, Kuri T, Blakqori G, Weber F, Ludewig B, Thiel V (2007) Coronavirus non-structural protein 1 is a major pathogenicity factor: implications for the rational design of coronavirus vaccines. PLoS Pathog 3(8):e109. https://doi.org/10. 1371/journal.ppat.0030109

52. Moshynskyy I, Viswanathan S, Vasilenko N, Lobanov V, Petric M, Babiuk LA, Zakhartchouk AN (2007) Intracellular localization of the SARS coronavirus protein $9 \mathrm{~b}$ : evidence of active export from the nucleus. Virus Res 127(1):116-121. https://doi.org/10.1016/j. virusres.2007.03.011

53. Demling R (2007) The use of anabolic agents in catabolic states. J Burns Wounds 6:e2

54. Yarasheski KE, Smith SR, Powderly WG (2005) Reducing plasma HIV RNA improves muscle amino acid metabolism. Am J PhysiolEndocrinol Metab 288(1):E278-E284. https://doi.org/10.1152/ ajpendo.00359.2004 
55. Huang W, Li C, Wang Z, Wang H, Zhou N, Jiang J, Ni L, Zhang XA, Wang DW (2020) Decreased serum albumin level indicates poor prognosis of COVID-19 patients: hepatic injury analysis from 2,623 hospitalized cases. Sci China Life Sci 63(11):1678-1687. https://doi.org/10.1007/s11427-020-1733-4

56. Kukla M, Skonieczna-Żydecka K, Kotfis K, Maciejewska D, Łoniewski I, Lara LF, Pazgan-Simon M, Stachowska E, Kaczmarczyk M, Koulaouzidis A, Marlicz W (2020) COVID-19, MERS and SARS with concomitant liver injury - systematic review of the existing literature. J Clin Med 9(5):1420. https://doi. org $/ 10.3390 / \mathrm{jcm} 9051420$

57. de la Rica R, Borges M, Aranda M, del Castillo A, Socias A, Payeras A, Rialp G, Socias L, Masmiquel L, Gonzalez-Freire M (2020) Low albumin levels are associated with poorer outcomes in a case series of COVID-19 patients in Spain: a retrospective cohort study. Microorganisms 8(8):1106. https://doi.org/10.3390/ microorganisms 8081106

58. Cena H, Maffoni S, Braschi V, Brazzo S, Pallavicini C, Vietti I, Portale S, Corradi E (2020) Position paper of the Italian association of medical specialists in dietetics and clinical nutrition (ANSISA) on nutritional management of patients with COVID-19 disease. Mediterr J Nutr Metab 13(2):113-117. https://doi.org/10.3233/ MNM-200425

59. Disser NP, De Micheli AJ, Schonk MM, Konnaris MA, Piacentini AN, Edon DL et al (2020) Musculoskeletal consequences of COVID-19. J Bone Joint Surg Am 102(14):1197-1204. https:// doi.org/10.2106/JBJS.20.00847

60. Daniel PM, Pratt OE, Spargo E (1977) The metabolic homœostatic role of muscle and its function as a store of protein. Lancet 2(8035): 446-448. https://doi.org/10.1016/s0140-6736(77)90622-5

61. Lindner D, Fitzek A, Bräuninger H, Aleshcheva G, Edler C, Meissner K, Scherschel K, Kirchhof P, Escher F, Schultheiss HP, Blankenberg S, Püschel K, Westermann D (2020) Association of cardiac infection with SARS-CoV-2 in confirmed COVID-19 autopsy cases. JAMA Cardiol 5(11):1281-1285. https://doi.org/10. 1001/jamacardio.2020.3551

62. Babapoor-Farrokhran S, Gill D, Walker J, Rasekhi RT, Bozorgnia B, Amanullah A (2020) Myocardial injury and COVID-19: possible mechanisms. Life Sci 253:117723. https://doi.org/10.1016/j.lfs. 2020.117723

63. Ahmadian E, Khatibi SMH, Soofiyani SR, Abediazar S, Shoja MM, Ardalan M, et al. Covid-19 and kidney injury: pathophysiology and molecular mechanisms. Rev Med Virol e2176. doi: 10.1002/rmv.2176.

64. Pormohammad A, Ghorbani S, Khatami A, Farzi R, Baradaran B, Turner DL, Turner RJ, Bahr NC, Idrovo JP (2020) Comparison of confirmed COVID-19 with SARS and MERS cases - clinical characteristics, laboratory findings, radiographic signs and outcomes: a systematic review and meta-analysis. Rev Med Virol 30(4):e2112. https://doi.org/10.1002/rmv.2112

65. Noor FM, Islam MM (2020) Prevalence and associated risk factors of mortality among COVID-19 patients: a meta-analysis. J Community Health 45(6):1270-1282. https://doi.org/10.1007/ s10900-020-00920-x

66. Roossinck MJ, Bazán ER (2017) Symbiosis: viruses as intimate partners. Annu Rev Virol 4(1):123-139. https://doi.org/10.1146/ annurev-virology-110615-042323
67. Reimand J, Isserlin R, Voisin V, Kucera M, Tannus-Lopes C, Rostamianfar A, Wadi L, Meyer M, Wong J, Xu C, Merico D, Bader GD (2019) Pathway enrichment analysis and visualization of omics data using g:Profiler, GSEA, Cytoscape and EnrichmentMap. Nat Protoc 14(2):482-517. https://doi.org/10. 1038/s41596-018-0103-9

68. Borges L, Pithon-Curi TC, Curi R, Hatanaka E (2020) COVID-19 and neutrophils: the relationship between hyperinflammation and neutrophil extracellular traps. Mediat Inflamm 2020:8829674 8829677. https://doi.org/10.1155/2020/8829674

69. Chau AS, Weber AG, Maria NI, Narain S, Liu A, Hajizadeh N, Malhotra P, Bloom O, Marder G, Kaplan B (2020) The longitudinal immune response to coronavirus disease 2019: chasing the cytokine storm. Arthritis Rheum 73:23-35. https://doi.org/10.1002/art. 41526

70. Liu H, Wang L-L, Zhao S-J, Kwak-Kim J, Mor G, Liao A-H (2020) Why are pregnant women susceptible to COVID-19? An immunological viewpoint. J Reprod Immunol 139:103122. https://doi.org/ 10.1016/j.jri.2020.103122

71. Castro P, Matos AP, Werner H, Lopes FP, Tonni G, Araujo Júnior E et al (2020) Covid-19 and pregnancy: an overview. Rev Bras Ginecol E Obstetrícia 42(7):420-426. https://doi.org/10.1055/s0040-1713408

72. Hayakawa S, Komine-Aizawa S, Mor GG (2020) Covid-19 pandemic and pregnancy. J Obstet Gynaecol Res 46(10):1958-1966. https://doi.org/10.1111/jog.14384

73. Sun B, Yeh J (2020) Mild and asymptomatic Covid-19 infections: implications for maternal, fetal, and reproductive health. Front Reprod Health 2:1. https://doi.org/10.3389/frph.2020.00001

74. Bian X-W (2020) The COVID-19 pathology team. Autopsy of COVID-19 patients in China. Natl Sci Rev 7(9):1414-1418. https://doi.org/10.1093/nsr/nwaa123

75. Dean M (2019) Glycogen in the uterus and fallopian tubes is an important source of glucose during early pregnancy $\dagger$. Biol Reprod 101(2):297-305. https://doi.org/10.1093/biolre/ioz102

76. Ahmed-Sorour H, Bailey CJ (1981) Role of ovarian hormones in the long-term control of glucose homeostasis glycogen formation and gluconeogenesis. Ann Nutr Metab 25(4):208-212. https://doi. org/10.1159/000176496

77. Wang A, Zhao W, Xu Z, Gu J (2020) Timely blood glucose management for the outbreak of 2019 novel coronavirus disease (COVID-19) is urgently needed. Diabetes Res Clin Pract 162: 108118. https://doi.org/10.1016/j.diabres.2020.108118

78. Michalakis K, Ilias I (2020) SARS-CoV-2 infection and obesity: common inflammatory and metabolic aspects. Diabetes Metab Syndr 14(4):469-471. https://doi.org/10.1016/j.dsx.2020.04.033

79. Mazumder A, Roy N. (2020) Cytokine storm in COVID-19 in diabetic patients: a review. Bangladesh J Infect Dis S46-9. https:// doi.org/10.3329/bjid.v7i00.50162

80. Pinto BGG, Oliveira AER, Singh Y, Jimenez L, Gonçalves ANA, Ogava RLT, Creighton R, Schatzmann Peron JP, Nakaya HI (2020) ACE2 expression is increased in the lungs of patients with comorbidities associated with severe COVID-19. 222(4):556-563. doi: https://doi.org/10.1093/infdis/jiaa332.

Publisher's note Springer Nature remains neutral with regard to jurisdictional claims in published maps and institutional affiliations. 